\title{
Effect of oxidation time on the tribological behavior of thermally oxidized commercially pure zirconium under dry sliding conditions
}

\author{
A. Alansari and Y. Sun* \\ School of Engineering and Sustainable Development \\ Faculty of Technology \\ De Montfort University \\ Leicester, LE1 9BH, UK \\ *Corresponding author: Email : ysun01@dmu.ac.uk; Tel: (44) 1162577072
}

\begin{abstract}
Thermal oxidation is an effective surface engineering technique to harden the surfaces of zirconium $(\mathrm{Zr})$ and its alloys for improvement in friction and wear performance. In the present investigation, commercially pure zirconium $(\mathrm{CP}-\mathrm{Zr})$ is oxidized at $650{ }^{\circ} \mathrm{C}$ for a wide range of times from $1 \mathrm{~h}$ to $72 \mathrm{~h}$ with the aim to study the effect of oxidation time on the tribological performance of CP-Zr. It is found that a dense, pore-free and adherent zirconium dioxide $\left(\mathrm{ZrO}_{2}\right)$ layer can be produced at the surface for oxidation times less than $12 \mathrm{~h}$. Further increasing oxidation time leads to the gradual development of pores in the inner part of the oxide layer and oxidation breakaway characterized by accelerated oxidation kinetics and crack formation. Oxidation time has a significant effect on the tribological behaviour of thermally oxidized CP-Zr under dry sliding conditions. The $6 \mu \mathrm{m}$ thick oxide layer produced by $6 \mathrm{~h}$ treatment possesses the lowest friction, best wear resistance and the highest load bearing capacity. On the other hand, the thicker oxide layers produced by longer treatment times show deteriorated tribological behavior. The results are discussed in terms of the morphology of the oxide layer and crack propagation in the oxide layer and the underlying diffusion zone.
\end{abstract}

Keywords: Zirconium, Thermal oxidation, Friction, Wear, Tribology 


\section{Introduction}

Zirconium and its alloys have found increasing applications in several industrial sectors including the nuclear power generation, the chemical processing and the biomedical industries, mainly due to the combination properties of neutron transparency, excellent corrosion resistance and good biocompatibility [1-3]. However, with a base hardness of about $200 \mathrm{HV}$, zirconium and its alloys have poor tribological properties and find limited applications in other fields of engineering [4]. Efforts have been made to improve the wear resistance of zirconium through extending the oxide film on the surface, mainly by thermal oxidation [4-7] and plasma electrolytic oxidation [8,9]. With a bulk hardness of 1200 to $1300 \mathrm{HV}$, a sufficiently thick $\mathrm{ZrO}_{2}$ film can provide zirconium with excellent resistance to abrasion and wear [4-9].

Thermal oxidation is thus an effective surface engineering technique to harden the surfaces of zirconium $(\mathrm{Zr})$ and its alloys for improvement in friction and wear performance. Unlike thermal oxidation of titanium where the rutile oxide layer formed tends to be fragile and flake off easily when it is thicker than about $2 \mu \mathrm{m}$ [10], thermal oxidation of zirconium can produce a thick and adherent $\mathrm{ZrO}_{2}$ layer without the danger of flaking off $[11,12]$. The adherent and protective nature of the thick oxide layer on zirconium can be explained by the plasticity of zirconium oxide at elevated temperatures [13].

Indeed, oxidized zirconium (OxZr) has recently been introduced as an alternative bearing in total joint arthroplasty for artificial hip and knee joints [3,6,14-16]. OxZr possesses a good combination of a ceramic bearing surface to resist wear and a tough metallic core to resist fracture. Both in vivo and in vitro tests demonstrate that, as compared to the most commonly used Co-Cr bearing, $\mathrm{OxZr}$ with a $\mathrm{ZrO}_{2}$ layer about $5 \mu \mathrm{m}$ 
thick offers several advantages, including reducing polyethylene (PE) wear and enhanced resistance to surface roughening caused by third body particles [16-20].

Most of the published reports on clinic use of $\mathrm{OxZr}$ is based on the commercial process, OXINIUM (Smith \& Nephew Inc.), which produces an $\mathrm{ZrO}_{2}$ layer about $5 \mu \mathrm{m}$ thick and an oxygen diffusion zone (ODZ) of 1.5 to $2 \mu \mathrm{m}$ thick on $\mathrm{Zr}-2.5 \mathrm{wt} \% \mathrm{Nb}$ alloy. The thicknesses of the oxide layer and ODZ, which can be controlled easily by altering processing conditions, are expected to have significant effects on the tribological and load bearing properties of OxZr. However, information in this respect is limited in open literature. In this investigation, commercially pure zirconium $(\mathrm{CP}-\mathrm{Zr})$ is oxidized at $650{ }^{\circ} \mathrm{C}$ for a wide range of times from $1 \mathrm{~h}$ to $72 \mathrm{~h}$. The effects of oxidation time on the morphology and the tribological performance of the resultant oxide layers are investigated in this work.

\section{Material and Methods}

The substrate material, CP-Zr grade $2(99.2 \%)$ had the following chemical composition (wt $\%$ ): $0.16 \mathrm{O}, 0.025 \mathrm{~N}, 0.05 \mathrm{C}, 0.005 \mathrm{H}, 0.2 \mathrm{Fe}, 0.2 \mathrm{Hf}$ and $\mathrm{Zr}$ (rest). The material (supplied by Goodfellow UK Ltd) was received in a sheet form of $1 \mathrm{~mm}$ thickness and was cut into specimens of $20 \mathrm{~mm} \times 15 \mathrm{~mm}$ dimensions. The specimens were manually ground using SiC grinding papers down to the $\mathrm{P} 1200$ grade to achieve a surface finish of $0.20 \mu \mathrm{m}\left(\mathrm{R}_{\mathrm{a}}\right)$. After ultrasonically cleaning in methanol for $10 \mathrm{~min}$, the specimens were then subjected to thermal oxidation treatment.

Thermal oxidation was carried out in an air furnace at a constant temperature of $650{ }^{\circ} \mathrm{C}$, for duration of $1 \mathrm{~h}, 6 \mathrm{~h}, 12 \mathrm{~h}, 24 \mathrm{~h}$ and $72 \mathrm{~h}$. The heating rate of the furnace was $20^{\circ} \mathrm{C}$ per minute. After thermal oxidation, the specimens were cooled down to room temperature slowly in the furnace. Furnace cooling took about $8 \mathrm{~h}$ from $650{ }^{\circ} \mathrm{C}$ to room temperature. 
The temperature of $650{ }^{\circ} \mathrm{C}$ was chosen based on many prior experiments. At lower temperatures, it would take a significantly longer time to produce a sufficiently thick (e.g. $5 \mu \mathrm{m}$ ) oxide layer. At higher temperatures, the substrate material would suffer from grain growth with deteriorated properties.

$\mathrm{X}$-ray diffraction (XRD) was conducted using $\mathrm{Cu}-\mathrm{K}_{\alpha 1}$ to identify the phases of thermally oxidized specimens. Surface hardness was measured using Indentec ZHV microhardness tester at various loads of $0.025-0.5 \mathrm{~kg}$. Metallographic cross sections of oxidized specimens were prepared following standard procedures. In order to have an enlarged view of the oxide layer, a ball crater of about $1 \mathrm{~mm}$ diameter was made on the oxidized surface using a $25.4 \mathrm{~mm}$ diameter steel ball. Optical and scanning electron microscopes were then used to examine the morphological and structural features of the specimens in the cross section and the ball crater.

Thermal oxidation for different times was expected to affect the surface roughness of the specimens. In order to eliminate the possible effect of surface roughness on tribological behavior, before wear testing the oxidized surfaces were polished using diamond polishing compounds to achieve a mirror-like surface finish of $0.05 \mu \mathrm{m}\left(\mathrm{R}_{\mathrm{a}}\right)$. This polishing operation removed about $0.5 \mu \mathrm{m}$ thick material from the surface and thus slightly reduced the thickness of each oxide layer. Dry sliding friction and wear tests were conducted using a pin-on-disk tribometer (Teer Coatings Ltd). Although oxidized zirconium is currently mainly used in the bio-implant operating environments, dry sliding tests were conducted in this work to assess the response of the specimens to mechanical actions without interference from corrosion. Once the optimum oxidation time has been identified, further tests will be conducted in saline or bovine serum solution, which will introduce corrosion and tribocorrosion aspects to the overall degradation process. During the dry sliding wear process, the specimen was rotating against an alumina ball (Grade $25 \mathrm{Al}_{2} \mathrm{O}_{3}$ ) of $8 \mathrm{~mm}$ 
diameter (produced by Trafalgar Bearings Ltd). The tests were conducted at room temperature $\left(22^{\circ} \mathrm{C}\right)$ without lubrication, at a constant rotation speed of $60 \mathrm{rpm}$ for duration of $3600 \mathrm{~s}$. For the wear track diameter of $8 \mathrm{~mm}$, these resulted in a sliding speed of $2.5 \mathrm{~cm}$ $\mathrm{s}^{-1}$ and a total sliding distance of $90.5 \mathrm{~m}$. During the test, a computer data acquisition system was used to continuously record the coefficient of friction (COF). Initially, small contact loads of $1 \mathrm{~N}$ to $5 \mathrm{~N}$ were used in the tests. But these could not generate any measurable wear to the oxidized specimens. Thus, higher contact loads, $10 \mathrm{~N}$ and $20 \mathrm{~N}$, were employed in this work. These generated an initial contact pressure of $1122 \mathrm{MPa}$ and $1414 \mathrm{MPa}$, respectively, based on the contact between $\mathrm{Al}_{2} \mathrm{O}_{3}$ and untreated $\mathrm{CP}-\mathrm{Zr}$. These contact pressures were sufficiently high to cause plastic deformation of the untreated $\mathrm{CP}$ $\mathrm{Zr}$ at the contact zone.

After sliding wear testing, stylus profilometer was used to measure the wear track profile at 4 different locations and the wear volume from each wear track was evaluated. All tests were repeated twice and the means results are presented. Optical microscope and scanning electron microscope (SEM) were used to examine the morphology of the worn surfaces. Efforts have been made by making a ball crater on the wear track to reveal the actual wear depth and any deformation and cracking behaviour below the wear surface.

\section{Results and Discussion}

\subsection{Morphological characterization of thermally oxidized specimens}

Fig. 1 shows typical cross sectional morphology of thermally oxidized specimens produced at $650{ }^{\circ} \mathrm{C}$ for various times. As expected, thermal oxidation produced an oxide layer (OL) at the surface and an oxygen diffusion zone (ODZ) at the subsurface. The thickness values of OL and ODZ, together with surface hardness values measured at two indentation loads, are summarized in Table 1. The OL had a dark and shiny appearance 
and adhered well with the underlying diffusion zone, in agreement with the observation of other investigators [4-7]. XRD analysis confirmed that the OL comprised monoclinic zirconium dioxide, $\mathrm{ZrO}_{2}$. Fig. 2 is a typical $\mathrm{XRD}$ pattern generated from the oxidized surface, showing that only two phases were detected, i.e. $\alpha-\mathrm{Zr}$ from the substrate and monoclinic $\mathrm{ZrO}_{2}$ from the surface OL. The thickness of the OL ranged from $3 \mu \mathrm{m}$ to 15.5 $\mu \mathrm{m}$ and increased with oxidation time, as expected for processes governed by thermal diffusion. The thickness of the ODZ ranged from $1.5 \mu \mathrm{m}$ to $12 \mu \mathrm{m}$ and also increased with oxidation time. It was noted that as compared to the OL, the ODZ was relatively thin, which can be explained by the slow transport of oxygen from the gas phase through the dense OL to the subsurface [7].

As a result of the formation of the OL and the ODZ, the surface hardness of $\mathrm{CP}-\mathrm{Zr}$ was significantly increased. At a small indentation load of $0.025 \mathrm{~kg}$, the surface hardness was increased from the based level about $270 \mathrm{HV}_{0.025}$ to about $900-1300 \mathrm{HV}_{0.025}$ depending on oxidation time: the longer the oxidation time, the higher the surface hardness. At a higher indentation load of $0.5 \mathrm{~kg}$, the surface hardness of the oxidized specimens decreased due to the substrate effect, but it was still much higher than that of the untreated specimen, demonstrating enhanced load bearing capacity by thermal oxidation treatment. The hardening effect induced by thermal oxidation was further confirmed by micro hardness profile measurements, shown in Fig. 3. Increasing oxidation time increased the hardening depth and the hardness across the OL and ODZ. It is interesting to note that the hardness of the $72 \mathrm{~h}$ treated specimen experienced a drop at a depth about $10 \mu \mathrm{m}$, which is in the inner part of the OL. This is due to the existence of pores in this region of the OL, shown in Fig. $4 d$.

From Fig. 1, it can be seen that the OLs produced by relatively short time oxidation $(1 \mathrm{~h}$ and $6 \mathrm{~h}$ ) were dense, pore-free and uniform in thickness, while the OLs produced by long 
time oxidation (e.g. $72 \mathrm{~h}$ ) were none uniform in thickness and contained pores in the inner part and cracks open to the surface. In order to have an enlarged view of the OLs, a ball crater was made on each oxidized surface and examined under microscope, as shown in Fig. 4. Clearly, the OL produced by $6 \mathrm{~h}$ oxidation was very dense and free from any pore formation (Fig. 4a). Increasing the oxidation time to $12 \mathrm{~h}$ led to the development of a small amount of pores in the inner part of the OL at the OL-ODZ interfacial region (Fig. 4b). Pore formation became more significant when the oxidation time was further increased to $24 \mathrm{~h}$, as shown in Fig. 4c, where pores can be seen both in the inner part of the OL and in the ODZ. Finally, after $72 \mathrm{~h}$ oxidation, the inner part of the resultant OL became extremely porous, with the porous zone extending towards the surface and the ODZ (Fig. 4d). Cracks can be seen in the OL of the $72 \mathrm{~h}$ oxidized specimen arising from the linkage of the pores.

Oxidation of $\mathrm{Zr}$ and its alloys is governed by two distinctly different kinetics laws associated with the well-known phenomenon of oxidation breakaway $[11,12,21]$. Below a certain critical oxidation time, the OL grows following the parabolic or cubic rate law [21]. Above the critical oxidation time, oxidation breakaway occurs, where the oxide layer growth is accelerated, entering a nearly linear growth regime [11,21]. The resulting OL after breakaway becomes less protective because of the formation of cracks and pores. Under the present thermal oxidation condition at $650{ }^{\circ} \mathrm{C}$, breakaway occurred after $72 \mathrm{~h}$ treatment, resulting in a porous OL with cracks and none-uniform growth: some regions in the OL was as thick as $26 \mu \mathrm{m}$, as compared to $15.5 \mu \mathrm{m}$ measured for the majority of the OL (Table 1). The present work also showed that oxidation breakaway was preceded by the gradual development of pores in the inner part of the OL (Fig. $4 b$ and 4c). In order to have a better understanding of the oxidation kinetics under the present experimental conditions, the OL thickness data in Table 1 was plotted in Fig. 5 in the logarithm scale. Clearly, the growth of the OL followed a quasi-parabolic rate law with an exponent term of 
0.41 , just below 0.5 expected for solid diffusion, a phenomenon commonly observed for oxidation of $\mathrm{Zr}$ [21]. After $72 \mathrm{~h}$ oxidation, the thick regions of the OL suffered from breakaway and followed a linear growth law, as shown by the dotted line in Fig. 5.

\subsection{Tribological behaviour}

Fig. 6 shows typical friction curves recorded during dry sliding for selected specimens. After an initial running-in stage, the untreated specimen exhibited steady state friction with a coefficient of friction (COF) about 0.5 under both $10 \mathrm{~N}$ and $20 \mathrm{~N}$ loads. No large difference in friction was found at the two contact loads. On the other hand, contact load had a significant effect on the frictional behavior of the oxidized specimens. At $10 \mathrm{~N}$, the 1 $\mathrm{h}, 6 \mathrm{~h}$ and $12 \mathrm{~h}$ oxidized specimens exhibited similar friction behavior, where after the running-in stage, the $\mathrm{COF}$ became stable around the value of 0.4 . However, higher friction was found for the $24 \mathrm{~h}$ and $72 \mathrm{~h}$ oxidized specimens under the contact load of $10 \mathrm{~N}$. In Fig. 7, the mean COF measured at $10 \mathrm{~N}$ was plotted against oxidation time. Clearly, COF showed a general trend of increasing with oxidation time and prolonged oxidation had a detrimental effect on friction. It thus seems that the development of pores in the OL had a negative effect on friction reduction.

When the contact load was increased to $20 \mathrm{~N}$, the oxidized specimens showed different frictional behavior. Only the $6 \mathrm{~h}$ oxidized specimen exhibited a relatively smooth frictional behavior with higher COF values than those at $10 \mathrm{~N}$ load (Fig. 6). The other oxidized specimens exhibited a clear transition in frictional behavior after a certain period of sliding, characterized by the sudden increase in friction to result in a friction spike and then a sharp decrease in friction to reach $\mathrm{COF}$ values characteristic of the untreated specimen (see Fig. 6). This transition marked the sudden breakdown of the OL as confirmed by further tests ended before and after the transition point. Fig. 8 shows typical wear track cross sectional 
profiles measured by profilometer. The wear tracks produced on the $1 \mathrm{~h}$ and $12 \mathrm{~h}$ oxidized specimens at $10 \mathrm{~N}$ were narrow and shallow, without any sign of OL breakdown and removal (Fig. 8a). However, the wear tracks produced on the same specimens at $20 \mathrm{~N}$ load were wide, rough and as deep as $35 \mu \mathrm{m}$, with the OL and ODZ being completely removed (Fig. 8a). A similar behavior was also observed for the $24 \mathrm{~h}$ and $72 \mathrm{~h}$ oxidized specimens. On the other hand, the $6 \mathrm{~h}$ oxidized specimen had the ability to resist the $20 \mathrm{~N}$ contact load without OL breakdown, as shown in Fig. 8b where the wear track profiles were narrow and shallow with wear depths confined within the OL. Clearly, the dense and pore-free OL on the $6 \mathrm{~h}$ oxidized specimen had the best load bearing capacity as compared to the OLs on other oxidized specimens. The OL on the $1 \mathrm{~h}$ oxidized specimen was obviously too thin to resist high contact loads. Although the OLs on the $12 \mathrm{~h}, 24 \mathrm{~h}$ and $72 \mathrm{~h}$ oxidized specimens were much thicker than that on the $6 \mathrm{~h}$ oxidized specimen, the pores developed in these OLs obviously had a detrimental effect on the loading bearing capacity during the dry sliding wear process.

The total material loss (TML) from each wear track was measured from the wear track profiles. Fig. 9 compares the obtained results for different specimens at the two contact loads. At $10 \mathrm{~N}$, except for the $72 \mathrm{~h}$ oxidized specimen, all other oxidized specimens were very effective in reducing TML of CP-Zr by two orders of magnitude. No breakdown of the OL was observed on these specimens at $10 \mathrm{~N}$ and wear occurred within the OL (Fig. 8). $6 \mathrm{~h}$ oxidation was the most effective in improving wear resistance of $\mathrm{CP}-\mathrm{Zr}$ at $10 \mathrm{~N}$ load. Such an effectiveness of the $6 \mathrm{~h}$ oxidized specimen was maintained at the higher contact load of $20 \mathrm{~N}$ because the OL was not worn through (Fig. 9). However, for the other oxidized specimens, their effectiveness in reducing TML of CP-Zr at $20 \mathrm{~N}$ was much reduced because the OLs were worn through (Fig. 9). The breakdown of the OL at $20 \mathrm{~N}$ 
led to much accelerated TML by two orders of magnitude. Clearly, the $6 \mathrm{~h}$ oxidized specimen exhibited the best wear resistance under both contact loads.

Typical surface morphology of the wear tracks produced on the oxidized specimens at the $10 \mathrm{~N}$ load is shown in Fig. 10. Many semi-circular shaped cracks were observed on the wear track surface. It is believed that these cracks were formed due to the tensile stress at the contact surface resulting from the sliding traction [22]. The tensile stress at the contact surface was sufficient to induce cracks in the brittle ceramic, $\mathrm{ZrO}_{2}$. It is interesting to note that despite the formation of numerous cracks at the contact surface, the OL maintained its integrity with the substrate without flaking and delamination (Fig. 10a-c). However, for the $72 \mathrm{~h}$ oxidized specimen, local failure of the OL was observed, which was associated with the pre-existing cracks formed during the prolonged oxidation (see Fig. 10d). This seems to correlate with the measured high friction (Fig. 7) and large TML (Fig. 9) for this specimen. Obviously, the OL produced by $72 \mathrm{~h}$ oxidation was no longer protective under tribological conditions.

As a result of the sliding motion, wear not only occurred to the test specimen but also to the alumina ball counterface. A flat wear scar was produced on the alumina ball. The size of the scar increased with sliding time. Fig. 11a shows the wear scar on the alumina ball after testing the $6 \mathrm{~h}$ oxidized specimen at $10 \mathrm{~N}$ for $3600 \mathrm{~s}$. The mean diameter of the scar is about $140 \mu \mathrm{m}$. This means that the actual contact area increased as sliding proceeded, resulting in lowered contact pressure. Although the calculated initial maximum Hertz contact pressure (1122 MPa) was sufficient to cause plastic deformation in the untreated material, as sliding proceeded, the degree of plastic deformation should be reduced due to the increased contact area and the reduced contact pressure.

Fig. 12 shows the morphology of the wear tracks produced at the higher contact load of $20 \mathrm{~N}$. Except for the $6 \mathrm{~h}$ oxidized specimen, the OL on all other specimens was worn 
through in the wear track, resulting a wide and deep wear track with a rough surface and many parallel scratch marks, a typical morphological feature of the worn surface of untreated CP-Zr. For the $6 \mathrm{~h}$ oxidized specimen, although the OL still maintained its integrity with the substrate, numerous closely-spaced semi-circular cracks formed in the wear track. It is anticipated that with further sliding for a longer time, this OL would be removed from the wear track, resulting a transition in friction and much accelerated TML. The wear scar on the alumina ball after testing the $6 \mathrm{~h}$ oxidized specimen at $20 \mathrm{~N}$ is shown in Fig. 11b. As compared to that produced at $10 \mathrm{~N}$, the scar produced at $20 \mathrm{~N}$ was larger. It is also interesting to note that cracks were observed at the edge of the wear track (Fig. 12d), leading to chipping of the OL. These types of cracks were induced by bending of the ceramic layer due to substrate deformation in the wear track [23].

Fig. 13 shows selected SEM images of the wear tracks produced at $10 \mathrm{~N}$ and $20 \mathrm{~N}$ loads. The semi-circular cracks can be clearly seen on the $10 \mathrm{~N}$ wear tracks, which show evidence of local fracture of the OL associated with the cracks (Fig. 13a), mild abrasion (Fig. 13a) and polishing (Fig. 13b). In the $20 \mathrm{~N}$ wear track on the $6 \mathrm{~h}$ oxidized specimen, the densely populated semi-circular cracks and local breakdown of the OL at the track edges can be clearly seen (Fig. 13c). It is also evident that the cracks were filled with wear debris from the tribo-system (Fig. 13d).

From the results presented above, it is clear that the effect of thermal oxidation time on the tribological behavior of $\mathrm{CP}-\mathrm{Zr}$ was closely associated with the structural feature of the resultant oxide layer. The dense, pore-free and sufficiently thick ( $6 \mu \mathrm{m}) \mathrm{OL}$ on the $6 \mathrm{~h}$ oxidized specimen exhibited better wear resistance than the dense but thinner OL by $1 \mathrm{~h}$ oxidation and the thicker but porous OLs by $12 \mathrm{~h}, 24 \mathrm{~h}$ and $72 \mathrm{~h}$ oxidation. From the results obtained, several interesting questions can also be raised here, regarding the sudden breakdown of the OL during sliding wear at $20 \mathrm{~N}$ load (Fig. 6), the integrity of the OL with 
the substrate despite the formation of numerous cracks in the wear track (Fig. 10), and the depth of penetration of the cracks.

In order to have a visual view of the actual wear depth and the penetration of the surface cracks, a ball crater was made on the wear track and then examined under a microscope. Fig. 14 shows two representative images. The cracks seen on the $10 \mathrm{~N}$ wear track surfaces (Fig. 10) were confined to the superficial zone of the OL and no cracks were found to have penetrated to the oxide layer-ODZ interface region (Fig. 14a). At $20 \mathrm{~N}$, only the wear track on the $6 \mathrm{~h}$ oxidized specimen was available for such examination (Fig. 14b). In this case, the cracks have penetrated through the OL and across the OL-ODZ interface into the ODZ (Fig. 14b). Deformation of the OL towards the substrate at $20 \mathrm{~N}$ load was also evident from Fig. 14b, which could be responsible for the bending type cracks seen at the edge of the wear tracks (Fig. 12d and Fig. 14b). The fact that the OL on the $6 \mathrm{~h}$ oxidized specimen still maintained its integrity with the substrate after sliding at $20 \mathrm{~N}$ load suggests that penetration of the surface cracks through the OL to the ODZ was not sufficient to cause the sudden breakdown of the OL. It is anticipated that once the cracks propagate further into the substrate, the OL would be broken down, leading to the observed transition in friction (Fig. 6) and the accelerated TML (Fig. 9). This also suggests that a thick ODZ would help to delay the breakdown of the OL and enhance the load bearing capacity of the oxidized specimen. Thus, an ideal thermally oxidized system for $\mathrm{Zr}$ should comprise a dense, porefree and sufficiently thick OL at the surface and a thick ODZ at the subsurface [7].

\section{Conclusions}

From the results obtained in this work, it can be concluded that thermal oxidation at 650 ${ }^{\circ} \mathrm{C}$ for duration less than $12 \mathrm{~h}$ produces a relatively thick, dense, pore free and adherent oxide layer at the surface and a thin oxygen diffusion zone at the subsurface. Such a 
combination of the oxide layer and the oxygen diffusion zone possesses the lowest friction, best wear resistance and highest load bearing capacity. Although prolonged oxidation can increase the thicknesses of the oxide layer and the oxygen diffusion zone, it leads to the gradual development of pores in the inner part of the oxide layer and finally the breakaway of oxidation characterized by accelerated oxide growth and crack formation in the oxide layer. The formation of pores in the oxide layer has detrimental effects on friction reduction, wear resistance and load bearing capacity. The oxide layer surface tends to suffer from cracking under the present dry sliding process, and the oxide layer suffers from sudden breakdown after a certain period of sliding contact motion. This can be associated with the propagation of the surface cracks through the oxide layer and then the oxygen diffusion zone to reach the oxygen diffusion zone-substrate interface.

\section{Acknowledgement}

One of the authors (AA) would like to thank the Saudi Cultural Bureau in London for proving a PhD scholarship to facilitate this research. The authors would also like thank Rachel Armitage and Liz O'Brien for their assistance with SEM.

\section{References}

[1] IAEA, Waterside corrosion of zirconium alloys in nuclear power plants, VIENNA, 1998, IAEA-TECDOC-996, ISSN 1011-4289.

[2] R.T. Webster, Zirconium for chemical processing applications, Met. Prog. 113 (2) (1978) 62-64.

[3] Jerome Chevalier, What future for zirconia as a biomaterial?, Biomaterials 27 (2006) $535-543$.

[4] J.C. Haygarth, L.J. Fenwick, Improved wear resistance of zirconium by enhanced oxide films, Thin Solid Films 118 (1984) 351-362.

[5] R. Ji, X.Y. Li, H. Dong, Ceramic conversion treatment of zirconium alloys to combat wear, Suf. Eng. 26 (2010) 30-36. 
[6] G. Hunter, C.M. Asgian, G.I. Hines, Methods of surface hardening zirconium alloys and resulting products, United States Patent, US 6447550, 2002.

[7] V. Pawar, C. Weaver, S. Jani, Physical characterization of a new composition of oxidized zirconium-2.5 wt $\%$ niobium produced using a two step process for biomedical applications, App. Suf. Sci. 257 (2011) 6118-6124.

[8] M. Sandhyarani, M. Ashfaq, T. Arunnellaiappan, M.P. Selvan, S. Subramanian, N. Rameshbabu, Effect of electrical parameters on morphology and in-vitro corrosion resistance of plasma electrolytic oxidized films formed on zirconium, Surf. Coat. Tech. 269 (2015) 286-294.

[9] Linlin Wang, Xin Hu, X. Nie, Deposition and properties of zirconia coatings on a zirconium alloy produced by pulsed DC plasma electrolytic oxidation, Surf. Coat. Tech. 221 (2013) 150-157.

[10] R. Bailey, Y. Sun, Unlubricated sliding friction and wear characteristics of thermally oxidized commercially pure titanium, Wear 308 (2013) 61-70.

[11] G.R. Wallwork, C.J. Rosa, W.W. Smeltzer, Breakaway phenomena in the oxidation of zirconium at 850 and $950{ }^{\circ} \mathrm{C}$, Corros. Sci. 5 (1965) 113-120.

[12] R.A. Ploc, An electron microscope study of breakaway oxidation of zirconium at 623 K, J. Nucl. Mater. 91 (1980) 322-328.

[13] D.L. Douglass, Oxide plasticity in the oxidation mechanism of zirconium and its alloys, Corros. Sci. 5(1965) 255-268.

[14] A.M. Patel, M. Spector, Tribological evaluation of oxidized zirconium using an articular cartilage counterface: a novel material for potential use in hemiarthroplasty, Biomaterials 18 (1997) 441-447.

[15] V. Good, K. Widding, G. Hunter, D. Heuer, Oxidized zirconium: a potentially longer lasting hip implant, Mater. Des. 26 (2005) 618-622.

[16] M.C. Galetz, E.W. Fleischmann, C.H. Konrad, A. Schuetz, U. Glatzel, Abrasion resistance of oxidized zirconium in comparison with CoCrMo and titanium nitride coatings for artificial knee joints, J Biomed Mater Res B: Appl Biomater. 93B (2010) 244-251.

[17] J.D. DesJardins, B. Burnikel, M. LaBerge, UHMWPE wear against oxidized zirconium and $\mathrm{CoCr}$ femoral knee components during force-controlled simulation, Wear 264 (2008) 245-256.

[18] K.A. Ezzet, J.C. Hermida, N. Steklov, D.D. D’Lima, Wear of polyethylene against zirconium femoral components, The Journal of Arthroplasty 27 (2012) 116-121.

[19] Massimo Innocenti, Fabrizio Matassi, Christian Carulli, Lorenzo Nistri, Roberto Civinini, Oxidized zirconium femoral component for TKA: a follow-up note of a previous report at a minimum 10 years, The Knee 21 (2014) 858-861. 
[20] J.K. Hofer, K.A. Ezzet, A minimum 5-year follow-up of an oxidized zirconium femoral prosthesis used for total knee arthroplasty, The Knee 21 (2014) 168-171.

[21] Tatsuo Maekawa, Bunpei Ishii, Oxidation of zirconium in air, Tans JIM 3 (1962) 203-209.

[22] Kenneth Holmberg, Anssi Laukkanen, Helena Ronkainen, Kim Wallin, Simo Varjus, A model for stresses, crack generation and facture toughness calculation in scratched TiN-coated steel surfaces, Wear 254 (2003) 278-291.

[23] Y. Xie, H.M. Hawthorne, A model for compressive coating stresses in the scratch adhesion test, Surf. Coat. Tech. 141 (2001) 15025.

Table 1: Summary of oxide layer and oxygen diffusion zone thicknesses and surface hardness of oxidized specimens

\begin{tabular}{ccccc}
\hline \multirow{2}{*}{$\begin{array}{c}\text { TO time } \\
(\mathrm{h})\end{array}$} & $\begin{array}{c}\text { Oxide layer } \\
\text { thickness }(\mu \mathrm{m})\end{array}$ & $\begin{array}{c}\text { Diffusion layer } \\
\text { thickness }(\mu \mathrm{m})\end{array}$ & HV0.025 & HV0.5 \\
\hline Untreated & 0 & 0 & 271 & 194 \\
1 & 2.9 & 1.6 & 934 & 276 \\
6 & 6.33 & 2.8 & 1039 & 353 \\
12 & 8.09 & 4.6 & 1079 & 401 \\
24 & 10.82 & 7.6 & 1173 & 564 \\
72 & $15.45\left(26^{*}\right)$ & 12.3 & 1281 & 665 \\
\hline
\end{tabular}

* OL thickness in thick regions 


\section{List of figure captions}

Fig. 1: Microscopic images of the cross sections of selected oxidized specimens, showing the oxide layer (OL) and the oxygen diffusion zone (ODZ).

Fig. 2: X-ray diffraction pattern generated from the thermally oxidized surface $\left(650{ }^{\circ} \mathrm{C} / 6\right.$ h). $\mathrm{Cu}-\mathrm{K}_{\alpha 1}$ radiation. The diffraction peaks were indexed according to the ICDD data files 99-101-0116 (for $\alpha-\mathrm{Zr}$ ) and 99-100-6688 (for monoclinic $\mathrm{ZrO}_{2}$ ).

Fig. 3: Microhardness profiles across the oxidized layers of the specimens treated for various times. The inset shows typical hardness indents made in the subsurface region for hardness profile acquisition.

Fig. 4: Microscopic images of ball craters made on the oxidized surfaces, showing the dense oxide layer produced by $6 \mathrm{~h}$ oxidation (a) and the development of pores in the inner part of the oxide layers produced by $12 \mathrm{~h} \mathrm{(b),} 24 \mathrm{~h}$ (c) and $72 \mathrm{~h}$ (d) oxidation.

Fig. 5: Oxide layer (OL) thickness as a function of thermal oxidation time at $650^{\circ} \mathrm{C}$, plotted in the logarithm scale. Two data points are used for the $72 \mathrm{~h}$ oxidized specimen, one for the thick region and another for the overall of the OL.

Fig. 6: Recorded coefficient of friction (COF) curves for the untreated and thermally oxidized (TO) specimens.

Fig. 7: Mean coefficient of friction (COF) measured at $10 \mathrm{~N}$ load.

Fig. 8: Typical wear track profiles measured for (a) $1 \mathrm{~h}$ and $12 \mathrm{~h}$ and (b) $6 \mathrm{~h}$ oxidized specimens, tested under $10 \mathrm{~N}$ and $20 \mathrm{~N}$ loads.

Fig. 9: Wear volume measured for various specimens at $10 \mathrm{~N}$ and $20 \mathrm{~N}$ loads.

Fig. 10: Microscopic images showing the wear tracks on the oxidized specimens tested under $10 \mathrm{~N}$ load.

Fig. 11: Microscopic images showing the wear scar on the alumina ball after sliding with the $6 \mathrm{~h}$ oxidized specimen under (a) $10 \mathrm{~N}$ and (b) $20 \mathrm{~N}$ load. The arrow indicates the sliding direction and the dotted line indicates the boundary of the contact area.

Fig. 12: Microscopic images showing the wear tracks on the oxidized specimens tested under $20 \mathrm{~N}$ load.

Fig. 13: SEM images showing the morphology of the wear track on the $12 \mathrm{~h}$ oxidized specimen tested under $10 \mathrm{~N}$ load ( $\mathrm{a}$ and $\mathrm{b}$ ) and on the $6 \mathrm{~h}$ oxidized specimen tested under $20 \mathrm{~N}$ load (c and d).

Fig. 14: Microscopic images showing the wear track and a ball crater made on the wear track on the (a) $24 \mathrm{~h}$ oxidized specimen after testing under10 $\mathrm{N}$ load and (b) $6 \mathrm{~h}$ oxidized specimen after testing under $20 \mathrm{~N}$ load. 


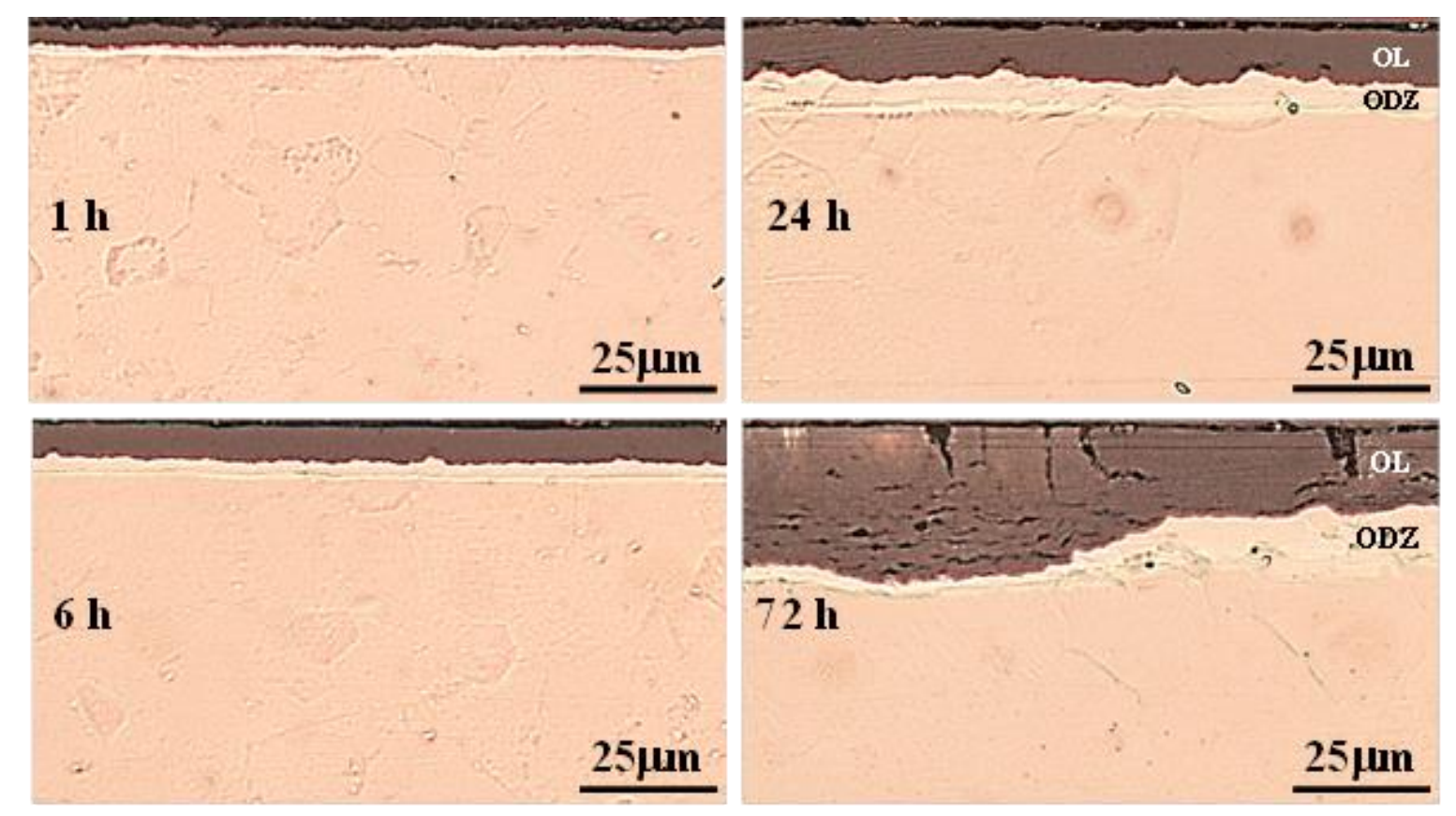

Fig. 1: Microscopic images of the cross sections of selected oxidized specimens, showing the oxide layer (OL) and the oxygen diffusion zone (ODZ).

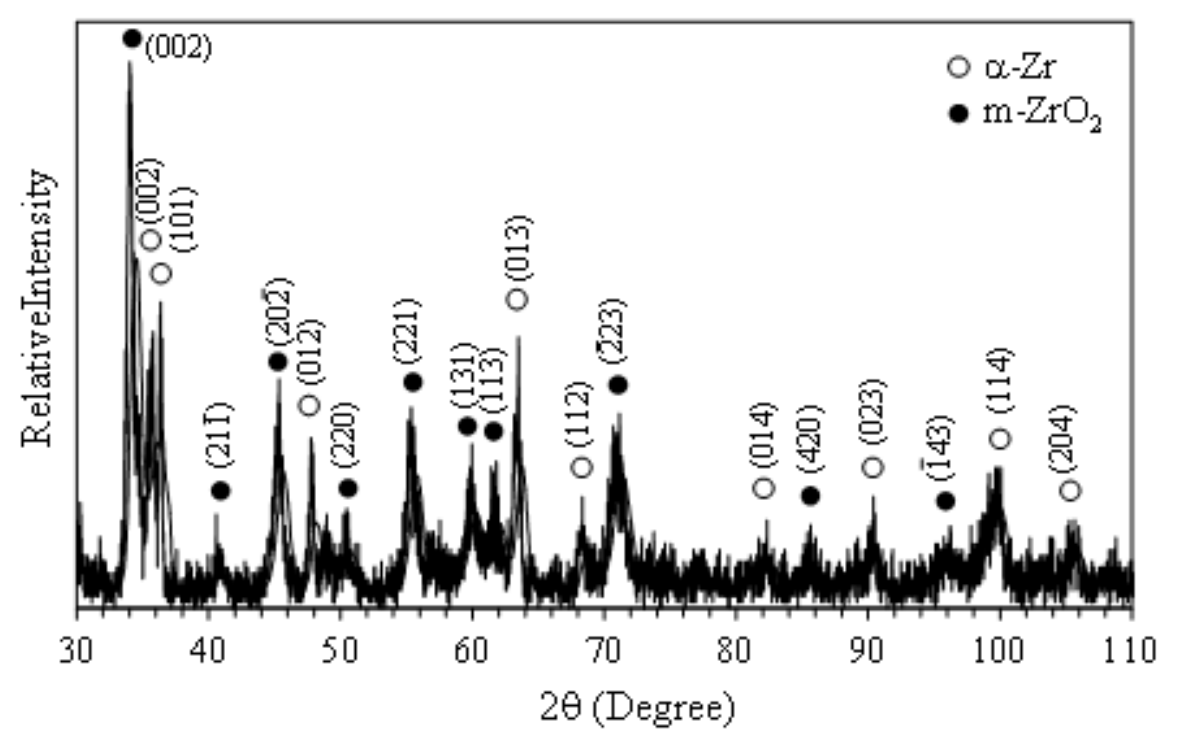

Fig. 2: X-ray diffraction pattern generated from the thermally oxidized surface $\left(650{ }^{\circ} \mathrm{C} / 6\right.$ h). $\mathrm{Cu}-\mathrm{K}_{\alpha 1}$ radiation. The diffraction peaks were indexed according to the ICDD data files 99-101-0116 (for $\alpha-\mathrm{Zr}$ ) and 99-100-6688 (for monoclinic $\mathrm{ZrO}_{2}$ ). 


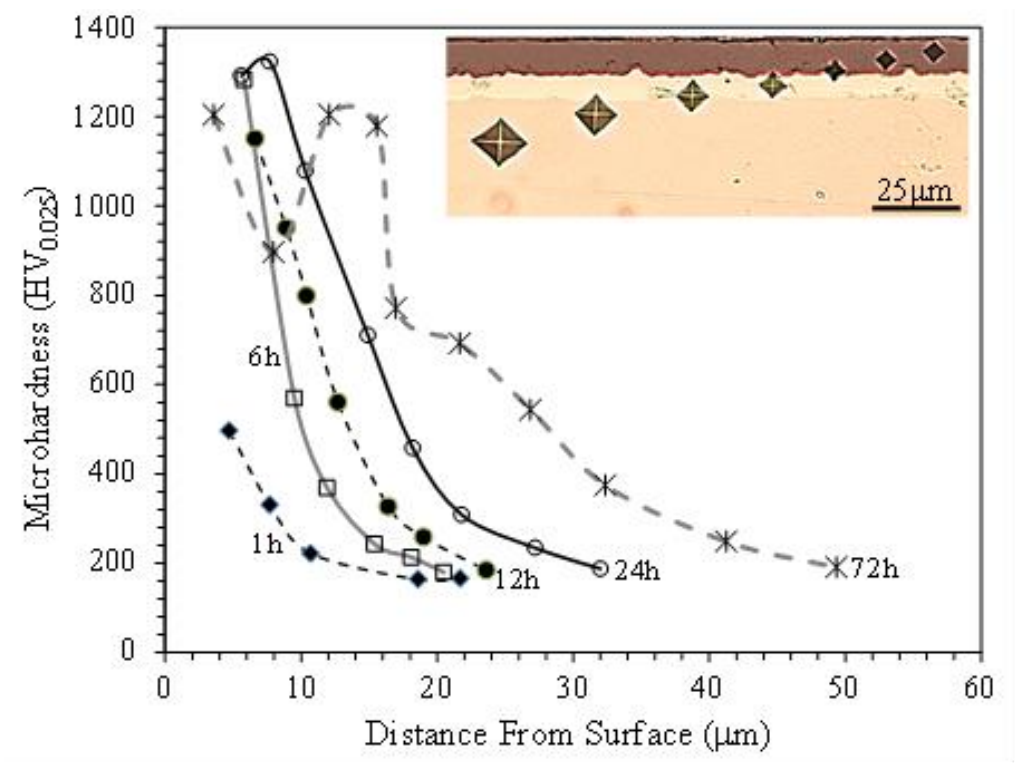

Fig. 3: Microhardness profiles across the oxidized layers of the specimens treated for various times. The inset shows typical hardness indents made in the subsurface region for hardness profile acquisition.
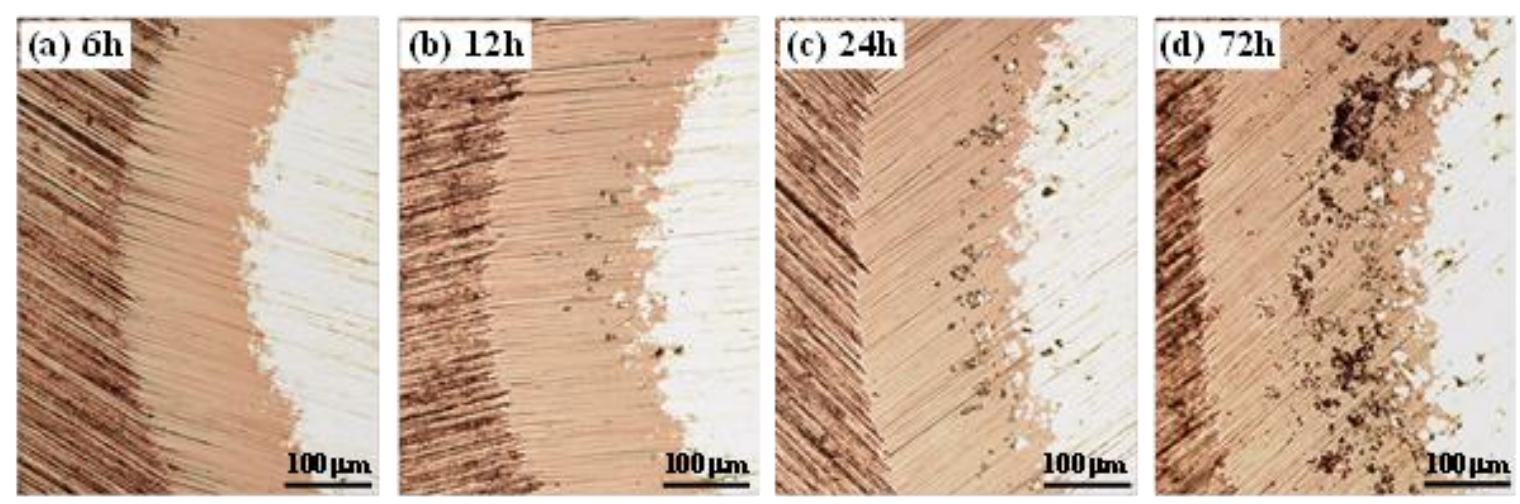

Fig. 4: Microscopic images of ball craters made on the oxidized surfaces, showing the dense oxide layer produced by $6 \mathrm{~h}$ oxidation (a) and the development of pores in the inner

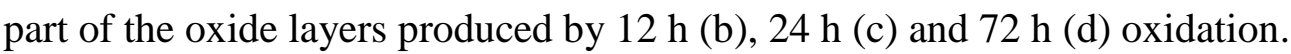




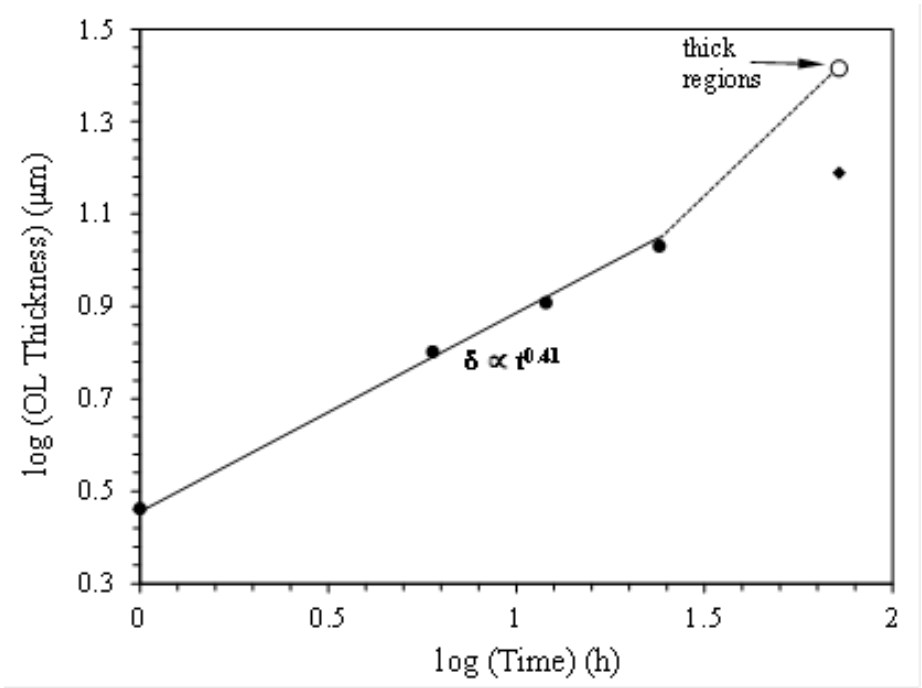

Fig. 5: Oxide layer (OL) thickness as a function of thermal oxidation time at $650^{\circ} \mathrm{C}$, plotted in the logarithm scale. Two data points are used for the $72 \mathrm{~h}$ oxidized specimen, one for the thick region and another for the overall of the OL.
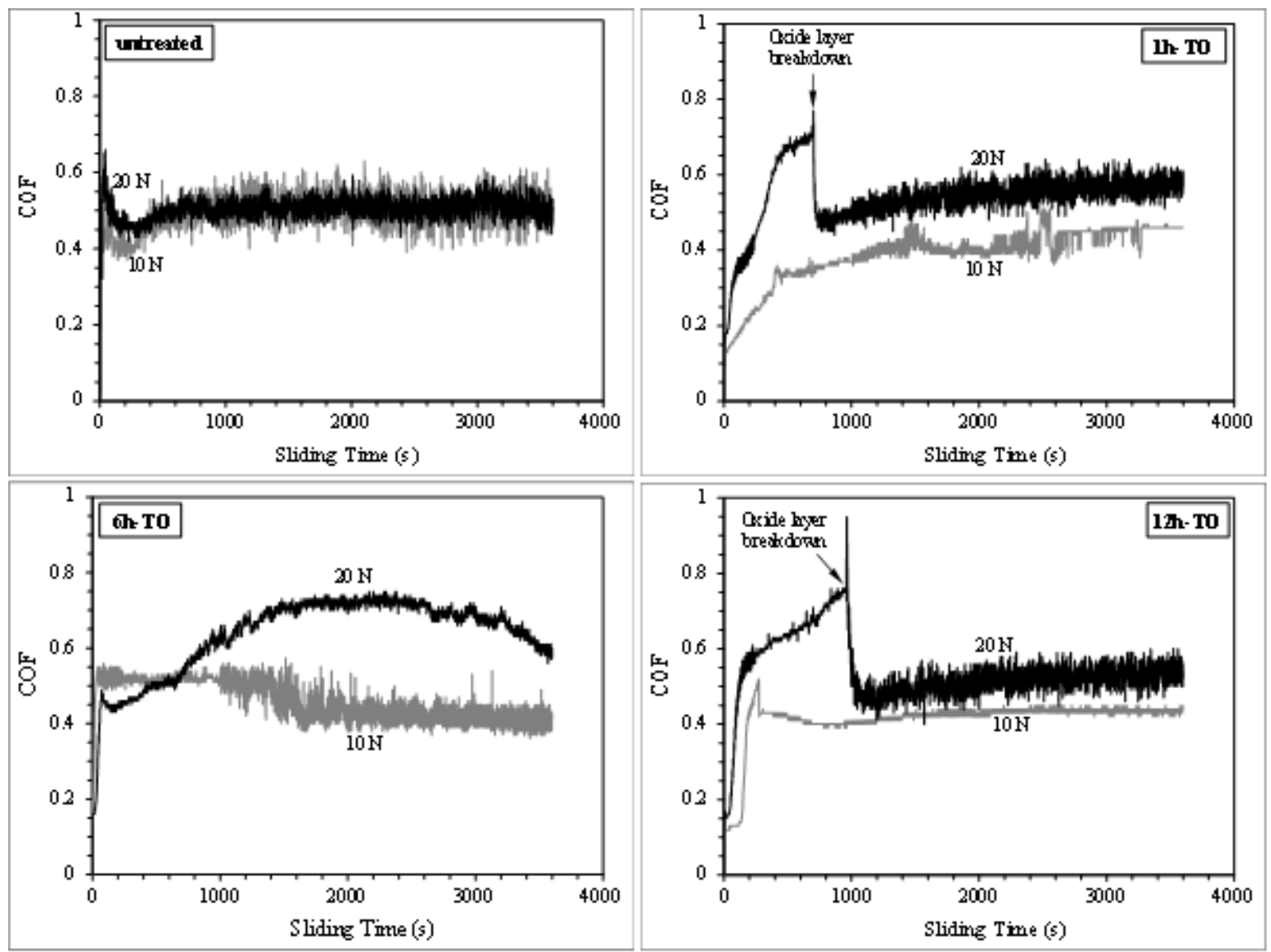

Fig. 6: Recorded coefficient of friction (COF) curves for the untreated and thermally oxidized (TO) specimens. 


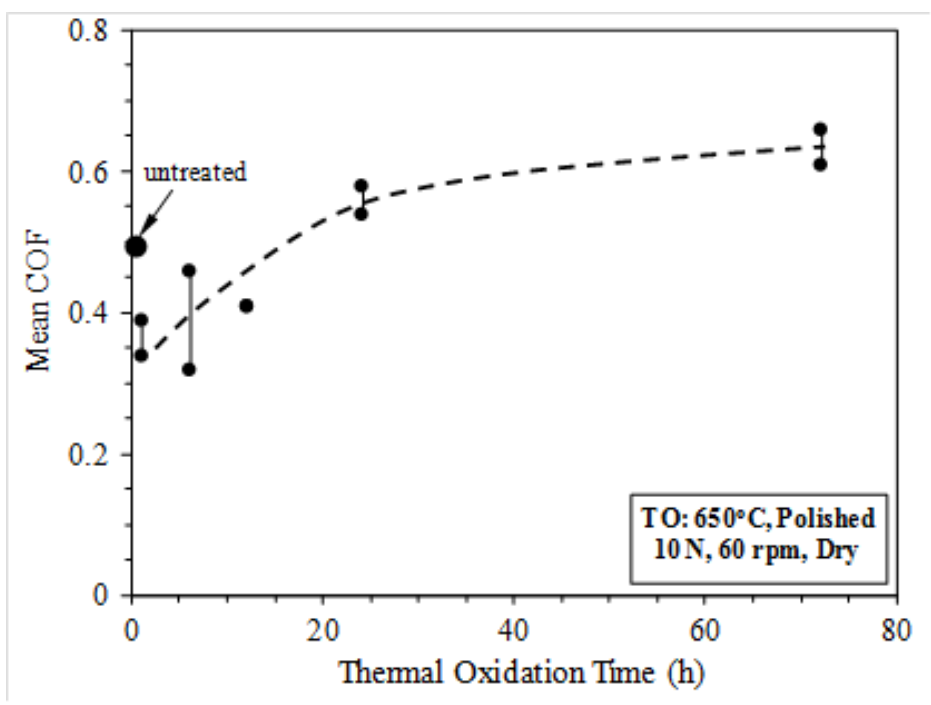

Fig. 7: Mean coefficient of friction (COF) measured at $10 \mathrm{~N}$ load.
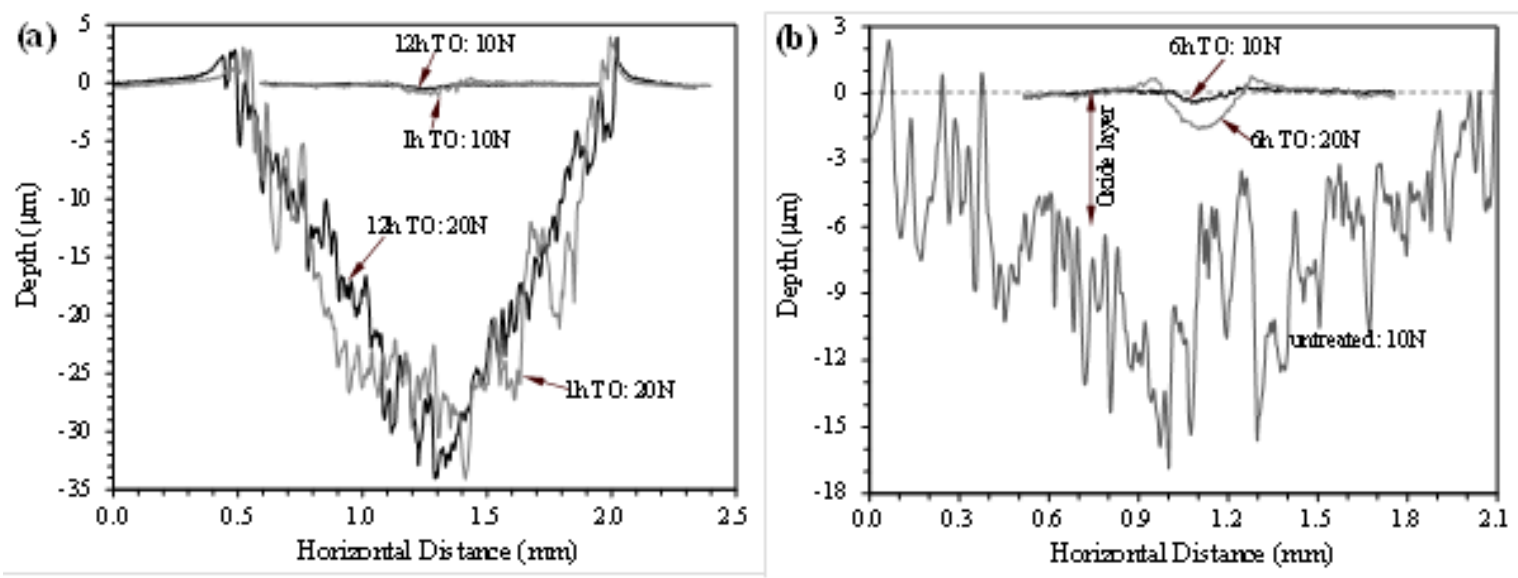

Fig. 8: Typical wear track profiles measured for (a) $1 \mathrm{~h}$ and $12 \mathrm{~h}$ and (b) $6 \mathrm{~h}$ oxidized specimens, tested under $10 \mathrm{~N}$ and $20 \mathrm{~N}$ loads.

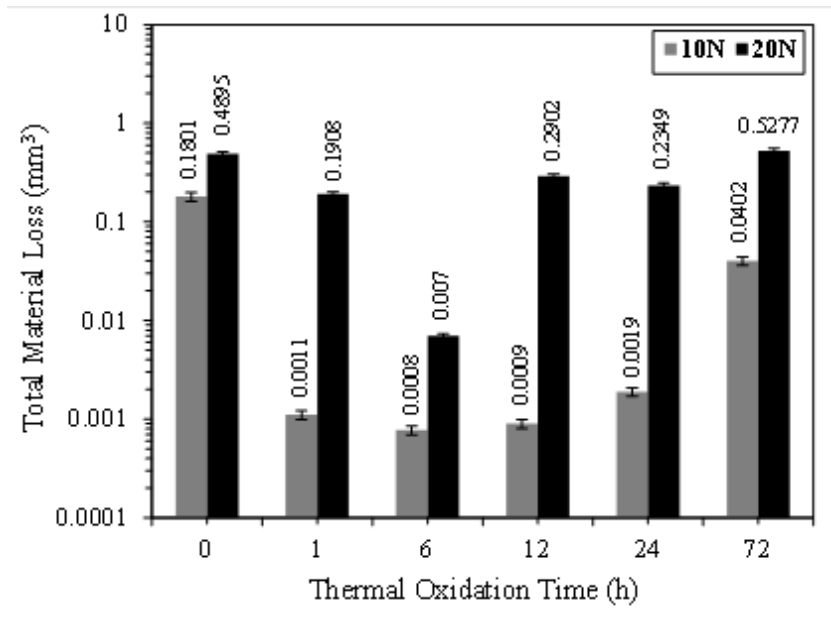

Fig. 9: Wear volume measured for various specimens at $10 \mathrm{~N}$ and $20 \mathrm{~N}$ loads. 

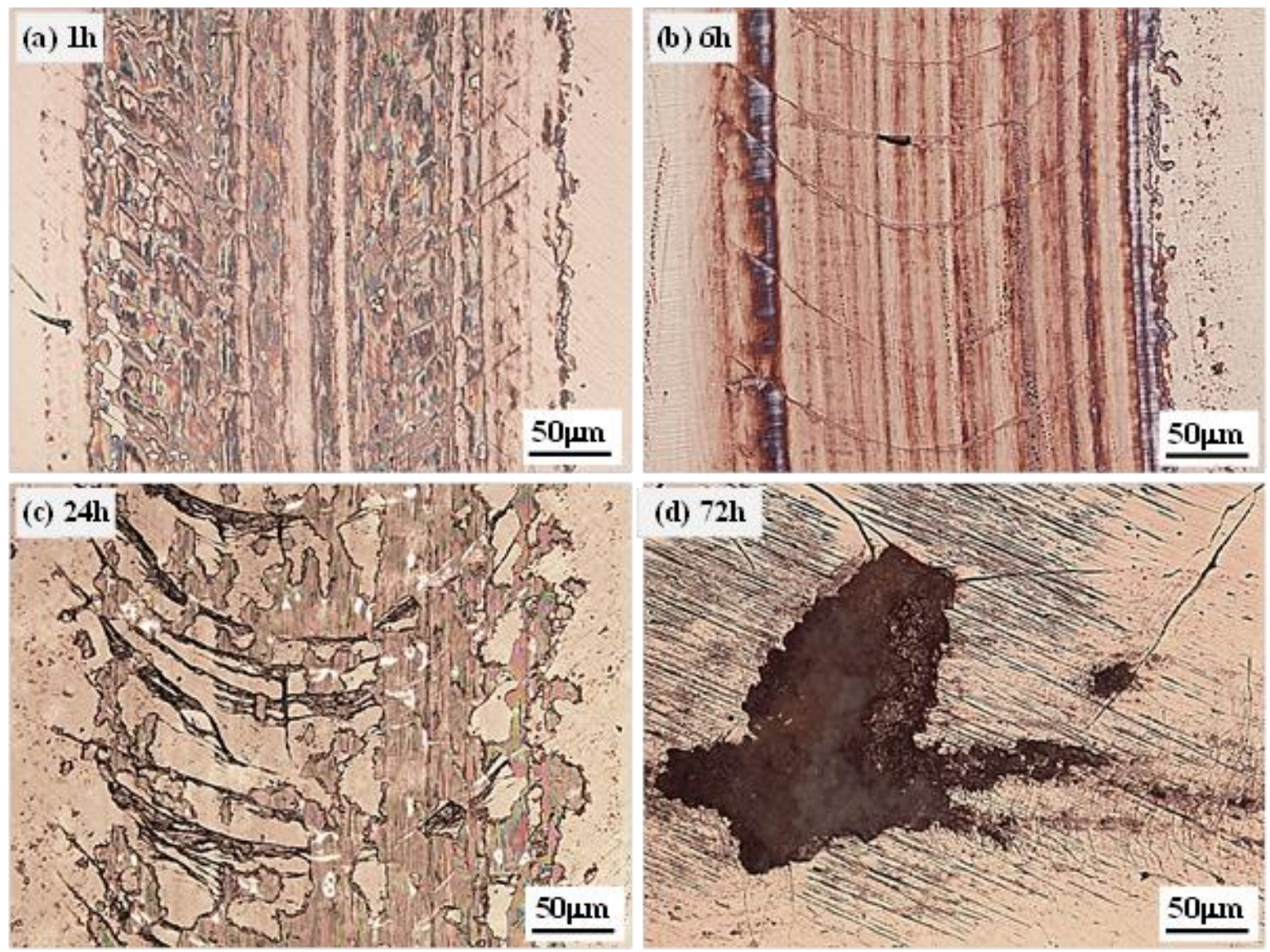

Fig. 10: Microscopic images showing the wear tracks on the oxidized specimens tested under $10 \mathrm{~N}$ load.
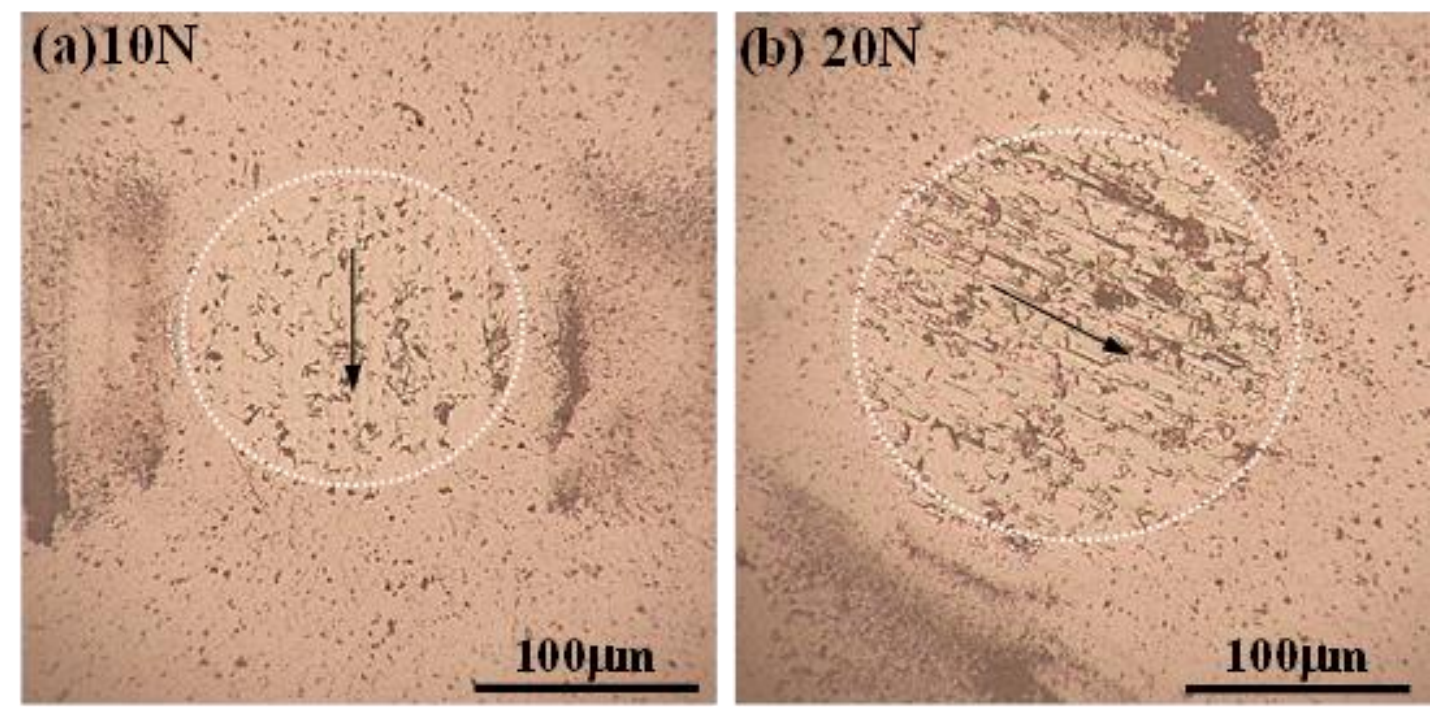

Fig. 11: Microscopic images showing the wear scar on the alumina ball after sliding with the $6 \mathrm{~h}$ oxidized specimen under (a) $10 \mathrm{~N}$ and (b) $20 \mathrm{~N}$ load. The arrow indicates the sliding direction and the dotted line indicates the boundary of the contact area. 

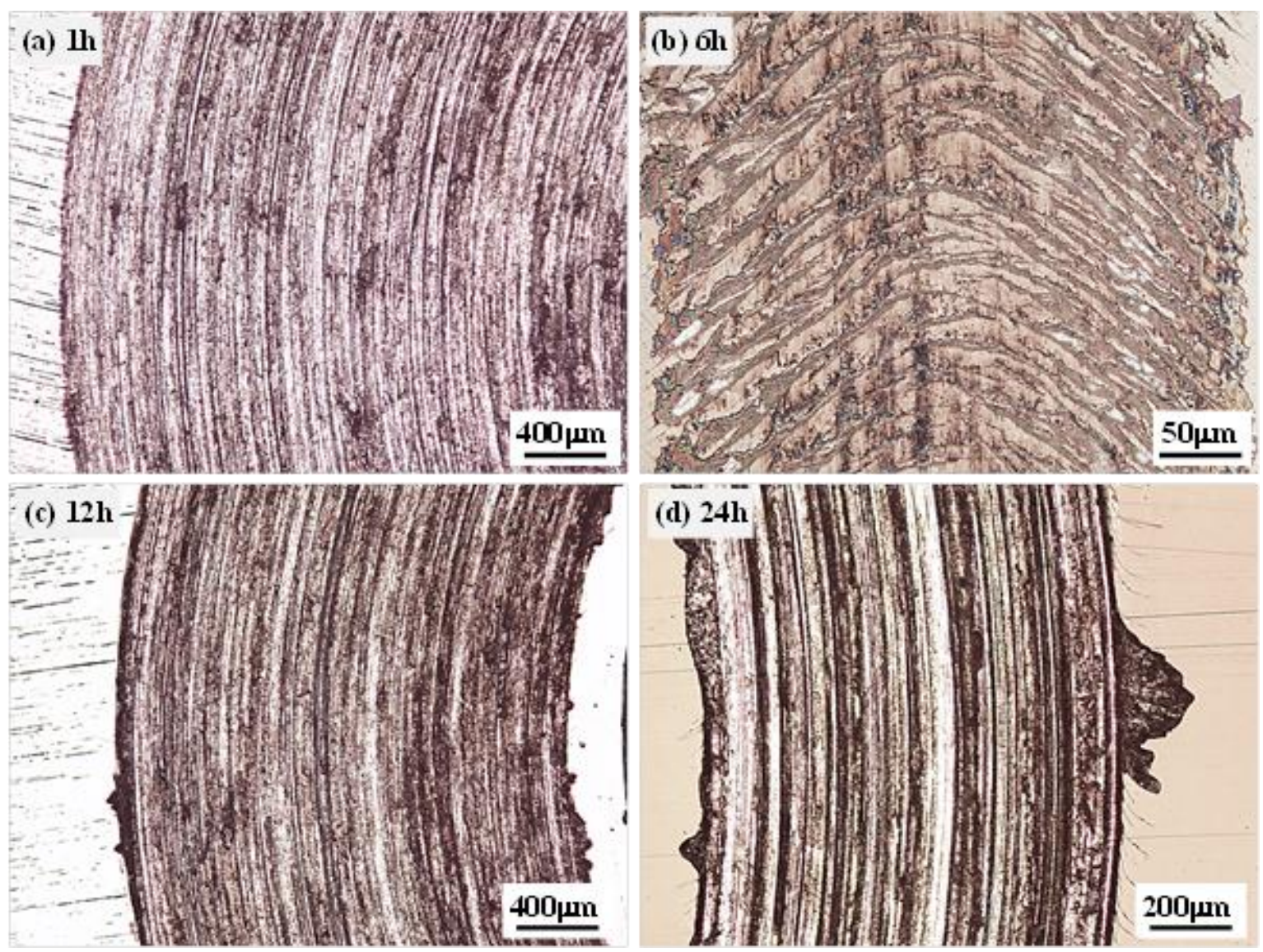

Fig. 12: Microscopic images showing the wear tracks on the oxidized specimens tested under $20 \mathrm{~N}$ load. 

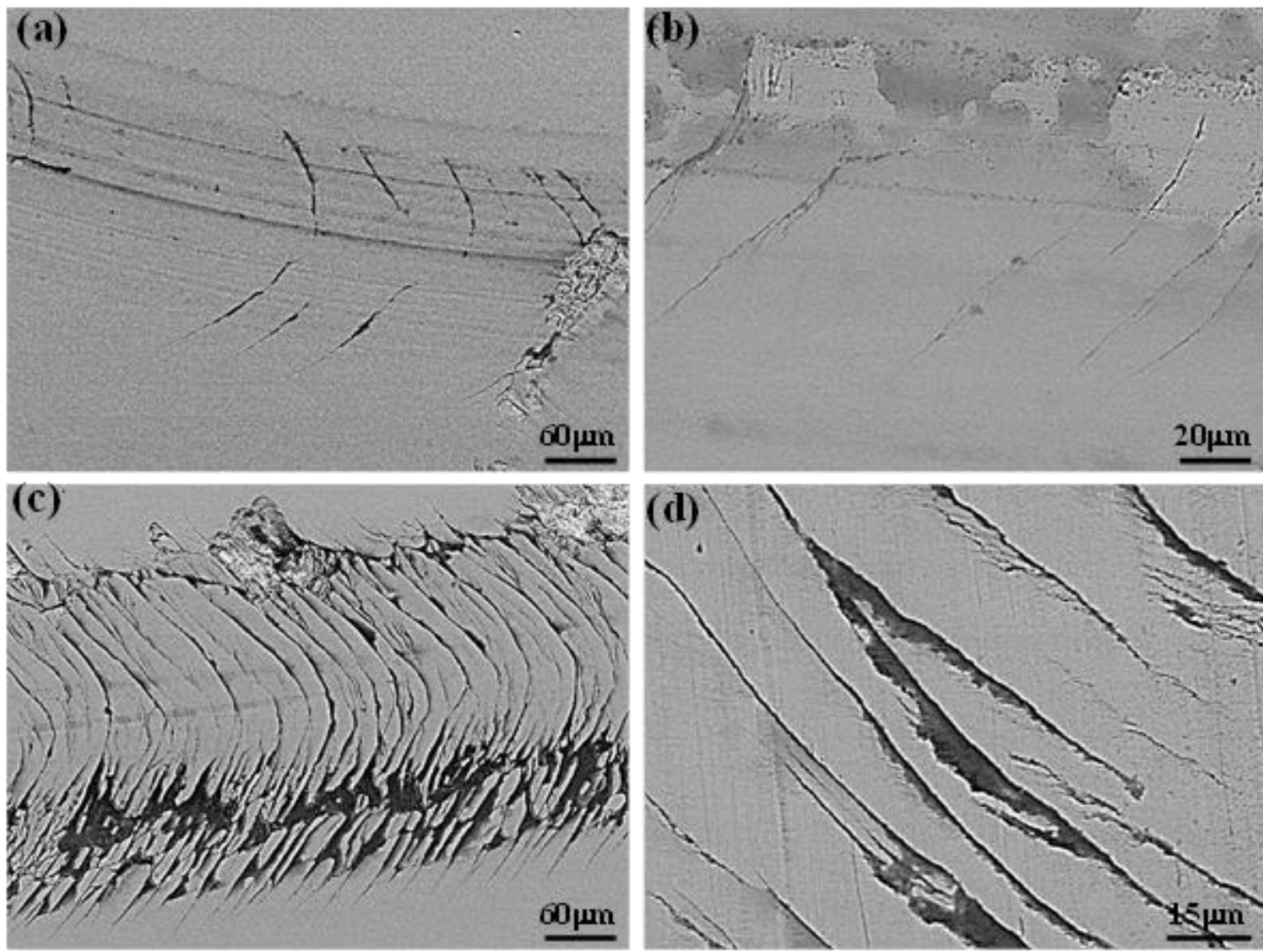

Fig. 13: SEM images showing the morphology of the wear track on the $12 \mathrm{~h}$ oxidized specimen tested under $10 \mathrm{~N}$ load ( $\mathrm{a}$ and $\mathrm{b}$ ) and on the $6 \mathrm{~h}$ oxidized specimen tested under $20 \mathrm{~N}$ load (c and d).
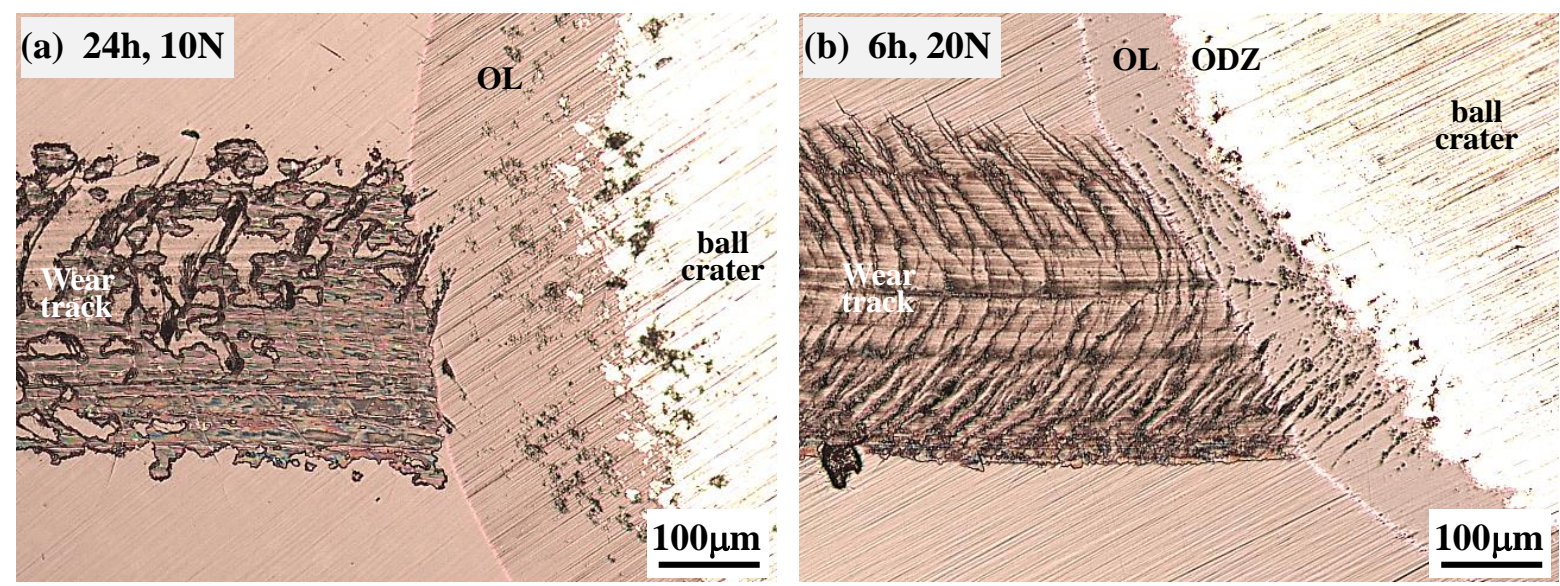

Fig. 14: Microscopic images showing the wear track and a ball crater made on the wear track on the (a) $24 \mathrm{~h}$ oxidized specimen after testing under10 $\mathrm{N}$ load and (b) $6 \mathrm{~h}$ oxidized specimen after testing under $20 \mathrm{~N}$ load. 